\title{
Original
}

\section{Caracterización por la imagen de las masas renales. Atlas por la imagen}

\author{
Javier Fernández Mena*, Armando Zuluaga Gómez**, Francisco Valle Díaz de la Guardia** \\ *Departamento de Radiología y Medicina Física de la Universidad de Granada. Servicio de Radiología \\ Diagnóstica de Clínica Inmaculada Concepción de Granada. ${ }^{*}$ Servicio de Urología. Hospital Universitario San \\ Cecilio. Granada. España.
}

\section{Resumen}

El estudio diagnóstico, análisis y caracterización de las masas renales y su comportamiento representa uno de los pilares maestros para la elaboración de una estrategia quirúrgica o terapeútica de otros órdenes, en la elaboración de un pronóstico y en el seguimiento de la eficacia terapeútica tanto en casos de patología benigna como maligna. La TC y la RMI representan, en la actualidad, los dos modos más fiables, eficaces y eficientes en tal tipo de análisis y caracterización con índices de sensibilidad y especificidad superiores el 87\% y con una fiabilidad diagnóstica superior al 90\% dentro de las masas renales, sean quísticas simples o complejas, de orden inflamatorio inespecífico o específico o de origen tumoral primario o secundario de la esfera renal.

El propósito de este estudio es el demostrar los principales parámetros de estudio mediante TC y RMI de tales tipos patológicos y correlacionarlos con los datos clínicos, patofisiológicos e histopatológicos para obtener datos paramétricos en arquitectura, densidad, intensidad de señal y comportamiento biológico que nos ayuden a comprender los cambios que se producen en el área renal y retroperitoneal derivados de tales patologías.

Palabras clave: Masa renal. Inflamación renal. Quistes renales. Tumores renales. TC en patología renal quística, inflamatoria y tumoral. RMI en patología renal quística, inflamatoria y tumoral. Estadiaje de tumores renales.

\section{Imaging characterization of renal masses. Image atlas \\ Abstract}

The diagnostic study, analysis and characterization of renal masses and their behavior is one of the key elements for elaborating a surgical or therapeutic strategy, determining the prognosis, and for the follow-up of treatment efficacy in patients with benign or malignant disease. At present, computed tomography (CT) and magnetic resonance imaging (MRI) are the two most reliable, effective and efficient instruments in this context - offering sensitivity and specificity values in excess of $87 \%$, with a diagnostic relaibility of over $90 \%$ in application to renal masses of a cystic or complex nature, with nonspecific or specific inflammatory characteristics, or of a primary or secondary neoplastic nature.

The aim of this study is to present the principal CT and MRI parameters in relation to renal pathology of this kind, correlating them to the clinical, physiopathological and histopathological data with a view to affording architectural, density, signal intensity and biological behavior parametric information of help in understanding the changes occurring in the renal and retroperitoneal regions secondary to such pathologies.

Keywords: Renal mass. Renal inflammation. Renal cysts. Renal tumors. CT in renal cystic, inflammatory and tumor disease. MRI in renal cystic, inflammatory and tumor disease. Staging of renal tumors.

A ctualmente, debido al serio incremento en el uso de las técnicas de imagen a nivel torácico y abdominal, el diagnóstico de masa renal, sea benigna o maligna, se plantea hasta en un 50\% de forma incidental y en pacientes asintomáticos. Pacientes con hematuria (56\% de los pacientes con cáncer renal), dolor en flanco (38\%), perdida de peso (27\%) y otros sintomas relacionados con la historia natural del cáncer renal, son dirigidos a las Unidades de Diagnóstico por Imagen en forma específica y, en caso de cánceres renales asociados a síndromes familiares hereditarios como el Von-Hippel-Lindau, la traslocación del cromosoma 3, la esclerosis tuberosa, el síndrome de BirtHog-Dubé o el del carcinoma papilar renal hereditario, es obligatorio el control de la población familiar relacionada. De cualquier forma, la estadística principal proviene de los casos en que no interviene la clínica o la historia familiar hereditaria. 
Probablemente, el incremento exponencial que ha sufrido la exploración ultrasonográfica en nuestros Centros Hospitalarios, su gran accesibilidad, su gran fiabilidad diagnóstica, bajo coste y con alta resolución espacial y la proliferación de las exploraciones TC abdominales desde Unidades ambulatorias y de encamación no Urológicas por diversos problemas, estén colaborando de una forma positiva en la identificación, caracterización, estadificación y evaluación de las posibilidades quirúrgicas de estas masas renales descubiertas incidentalmente.

Cuando hablamos de masa renal debemos, obligatoriamente, de incluir a todos los procesos benignos y malignos que ocupen, distorsionen y afecten al parénquima renal y su entorno, en independencia de su etiología, forma y volumen. Aquí deberemos de incluir a las formaciones quísticas, pseudotumores, neoplasias, enfermedades inflamatorias y lesiones traumáticas.

Cualquier masa renal, de cualquier etiología, se comporta con cambios de la forma y volumen, con alteraciones vasculares y con la creación de un síndrome compartamental en mayor o menor escala. La comprobación diagnóstica de estos efectos se realiza mediante Ultrasonografía y US Doppler, estudios TC sin y con medio de contraste yodado, UIV y Resonancia Magnética de Imagen ${ }^{1-16}$.

\section{La Ultrasonografia}

Es una técnica no invasiva, sin empleo de radiación ionizante, de gran accesibilidad, bajo coste y amplio grado de caracterización tisular en relación al comportamiento de los órganos y sus lesiones en la interacción con las ondas mecánicas. Básicamente, la Ultrasonografía nos informa de:

1. Topografia del órgano.

2. Morfología del órgano.

3. Volumetría.

4. Diferenciación de estratos tisulares, ecoarquitectura del parénquima.

5. Estado de las vias excretoras.

6. Interfases del entorno renal o espacio perinéfrico.

7. Arquitectura vascular, distribución y características del flujo.

8. Mediante el uso de ecopotenciadores, la valoración de lesiones isquémicas, traumáticas, tumorales, inflamatorias u obstructivas.

\section{La Tomografia Axial Computarizada (TC)}

Es la técnica de elección para la caracterización de las lesiones renales. El protocolo de TC incluye imágenes sin medio de contraste y con medio de contraste en dos fases:

A. Arterial y diferenciación cortico-medular.

B. Nefrográfica. La TC nos permite la observación de:

1. Celda renal y estado morfológico y en densidad de las fascias renales, espacio perinéfrico y de los septos-puente cápsulo-fasciales, cápsula-capsulares y transversos.

2. Morfología, contornos y volumetría del órgano;

3. Presencia de abombamientos y distorsiones del eje renal.

4. Densidad basa y presencia de calcificaciones puntiformes.

5. Estado basal de la vía excretora urinaria.

6. Análisis de la masa renal y afectación de espacios: (a) renal;(b) renal y sinusal; (c) perinéfrico; (d) fascial; (e) a distancia.

7. Análisis del comportamiento vascular arterial y venoso.

8. Análisis de afectación linfática local, locoregional y a distancia.

9. Análisis de afectación venosa trombótica local, loco-regional y a distancia.

10. Análisis de afectación metastásica visceral.

El estudio sin medio de contraste yodado no permite clasificar, definitivamente, una masa como candidata a cirugía o no. Sugiere etiología y comportamiento biológico. El realce de una masa con medio de contraste yodado es el criterio más determinante para determinar si una masa es quirúrgica o no. En TC se puede medir con la comparación de la densidad basal y con el medio de contraste yodado intravenoso. Se considera realce positivo cuando la masa incrementa sus coeficientes de atenuación por encima de 20 unidades Hounsfield. Realces en densidad TC indeterminados y inferiores a 10 unidades Hounsfield deben de someterse a control o a protocolos de diagnóstico que incluyan otros estudios para su filiación.

En las masas sólidas y homogéneas se puede utilizar el análisis densitométrico o mapa de la distribución de los coeficientes de atenuación a la radiación $X$ en una región amplia de interés pero, en lesiones complejas de tipo quístico, necrótico o hemorrágico pueden existir problemas de caracterización. En estos casos se requieren varias medidas y 
el asegurarse que la marca de la región de interés se efectúe con los mismos parámetros en la TC sin y con medio de contraste yodado IV De cualquier forma, las mediciones de densidad en las masas renales pueden, en ocasiones, ser inconsistentes y poco específicas y el problema se agrava con lesiones de poco diámetro incluidas en el parénquima renal, sin abombamiento de los contornos y escasamente visibles en los estudios TC basales.

Este problema se agrava con el denominado "pseudorrealce" con incrementos superiores a 10 UH que experimentan los quistes intraparenquimatosos con diámetro inferior a $20 \mathrm{~mm}$ en determinadas ocasiones.

\section{La Resonancia Magnética de Imagen (RMI)}

Aporta al diagnóstico y caracterización de las masas renales los siguientes parámetros:

1. Volumen y localización de la lesión ocupante de espacio.

2. Características de la señal basal de la masa en secuencias potenciadas $\mathrm{T} 1$, densidad y $\mathrm{T} 2$.

3. Características de la lesión con realce de contraste paramagnético (imágenes vasculares).

4. Características de la lesión en secuencias de inversión-recuperación y supresión grasa.

5. Mapeo del área retroperitoneal, abdominal y visceral en relación con patología neoplásica primaria.

6. Análisis del estado vascular venoso y linfático del hilio renal y áreas linfáticas retroperitoneales.

7. Análisis de afectación del estrato graso perinéfrico.

8. Visualización de la cápsula renal, la pseudocápsula tumoral y alteraciones del patrón capsular.

9. Identificación de áreas quísticas, necróticas y caracterización del estruma tumoral y parenquimal adyacente normal.

Si estimamos toda esta serie de información, convendremos en que si estudiamos cualquier caso problema, identificado primariamente, como masa renal con parámetros Ultrasonográficos, en TC y RMI podemos valorar de primera intención:

- Lesión.

- Localización.

- Tamaño.

- Volumen.

- Características ecoarquitecturales.
- Características en densidad.

- Características en señal.

- Patrón vascular.

- Relaciones con parénquima sano.

- Relaciones extrínsecas al órgano huésped.

Estos datos, sometidos a parámetros de arquitectura tumoral en base a datos histopatológicos, nos van a permitir la diferenciación de lesiones de comportamiento, básicamente, benigno de otras lesiones con comportamientos tendentes o de malignidad. El espectro de tales lesiones incluyen patología quística, inflamatoria inespecífica y específica, tumoral benigna y maligna.

\section{LESIONES QUÍSTICAS}

La lesiones quísticas renales simples son las más frecuentes. No obstante, una lesión quística puede complicarse por infección o hemorragia y mostrar manifestaciones radiológicas complejas que hacen necesario un diagnóstico diferencial y protocolos diagnósticos de imagen complementarios al inicial.

Bosniak $^{1,2}$, efectuó una clasificación de las lesiones quísticas renales por categorias, hallazgos $\mathrm{y}$ tipos de control o seguimiento de tales lesiones.

La Categoría I define la lesión como densidad agua, sin septos o calcificaciones, ausencia de polos sólidos y sin realce a la administración de medio de contraste yodado IV. En Ultrasonografía aparecería como una lesión sin pared discernible, anecogénica pura y sin alteración del parénquima renal adyacente. En RMI se comportaría como una lesión de intensidad de señal homogénea, hipointensa en secuencias $\mathrm{T} 1$ e hiperintensa en secuencias $\mathrm{T} 2$, sin pared discernible y con ausencia de realce paramagnético. Su clasificación sería de quiste simple benigno y no requeriría ningún tipo de evaluación posterior.

La Categoría II, define una lesión con septos finos, calcificaciones lineales continuas o discontinuas o lesiones densas homogéneas pero que no experimentan realce a la administración de medios de contraste yodado IV. en TC o paramagnéticos en RMI. su clasificación es de lesión benigna mínimamente complicada y no precisa cirugía ni seguimiento.

La Categoría II F, exhibe septos finos en su interior, realce evidente en paredes o septos, mínimo grado de engrosamiento de la pared, calcificación grosera o nodular, lesiones intrarrenales densas sin realce y ausencia de realce medible en las lesiones 
descubiertas con incremento de la densidad radiológica. Se consideran masas quísticas moderadamente complicadas y precisan seguimiento.

La Categoría III, muestra engrosamientos lisos o irregulares de la pared o de los septos intraquísticos y existencia de realce medible en TC y RMI. Se consideran masas indeterminadas y precisan de primera instancia cirugía.

La Categoría IV muestra realces nodulares fuera de la pared y de los septos interpuestos en el área quística compleja. En realidad, se trata de neoplasias quisticas y precisan cirugía y estadificación.

Cuando una lesión quística presenta alguno de los siguientes hallazgos:

- Densidad superior a 20 UH.

- Calcificación.

- Presencia de septos.

- Múltiples locus quísticos.

- Engrosamiento parietal.

- Nodularidad o realce al contraste yodado intravenosa o paramagnético en RMI.

Se debe de hablar de "masa quística" y puede corresponderse con algunas de las formas del carcinoma de células renales.

La formaciones quísticas que responden a las categorías I, II y IV son fáciles de diagnosticar y de determinar su protocolo de actuación pero en las categorías II F y III, moderadamente complicadas o indeterminadas y que requieren cirugía en la mayoría de las ocasiones, es difícil de establecer una decisión en primera instancia precisan de un protocolo de diagnóstico por imagen y toma de muestras histológicas por biopsia con frecuencia. El diagnóstico diferencial es relevante.

La clasificación de Bosniak, aunque se estableció en base a los hallazgos en TC sin y con medio de contraste, debe hacerse extensiva a los parámetros que analiza la Ultrasonografía y la RMI sin y con medio de contraste paramagnético. La RMI suele precisar mejor los septos, engrosamientos de los mismos y parietales que la TC y, en casos complejos se debe recurrir siempre a esta técnica de imagen para la mayor precisión en la categorización de las masas quísticas según la clasificación de Bosniak.

Los quistes pequeños y no complejos suelen ser asintomáticos. Los de gran volumetría pueden provocar sensación de presión, episodios de hematuria, policitemia y ectasia de vías excretoras y deben ser puncionados o esclerosados o intervenidos por vía laparoscópica.
Los quistes renales complicados incluyen a los quistes hemorrágicos, quistes infectados y quistes con calcificación parietal. La hemorragia se presenta en un 6\% de todos los quistes renales. En pacientes con riñones poliquísticos se observa la hemorragia en un $68 \%$ de estos pacientes. La hemorragia aguda provoca un incremento homogéneo de la densidad (40-90 UH) y disminuye a lo largo de los días. Estos cambios de densidad no se afectan por el medio de contraste yodado IV. La sangre en el interior del quiste puede provocar una reacción inflamatoria en la pared del quiste y desarrollar un tejido de granulación vascular que puede mostrar realce al medio de contraste, engrosar la pared del quiste y causar, finalmente, su calcificación. El incremento de densidad en el quiste también puede deberse a un alto contenido en proteínas y a quistes con "leche cálcica". La RMI diferencia estas formaciones hemorrágicas de tumor. La aspiración del material del quiste y su análisis citológico y bioquímico es fundamental. Contenidos en sangre coagulada, alta concentración de proteínas y LDH, citología positiva e irregularidades en la pared de la formación quística son indicativos de tumor.

Alrededor del 3\% de las formaciones quísticas tienen calcificación parietal, habitualmente en forma de "cáscara de huevo". Se observan en combinación con incrementos homogéneos del grosor parietal. La mayor parte de estos hallazgos se corresponden con los cambios que un quiste simple experimenta por sangrado o infección previa. En un $20 \%$, las calcificaciones parietales pueden expresar una transformación maligna. Los quistes calcificados benignos tienen una membrana externa calcificada y no se acompañan de realces al medio de contraste yodado IV.

\section{La enfermedad de Pringle-Bourneville/ Esclerosis tuberosa}

Se caracteriza por un retraso mental y lesiones cutáneas (adenomas sebáceos). Representa una enfermedad neurocutánea hereditaria autonómica dominante con expresión variable. La expresión quística renal es frecuente en la esclerosis tuberosa y se caracterizan por células cilindricas eosinofílicas tapizando los quistes. Los angiomiolipomas, hamartomas renales, se muestran múltiples y bilaterales y se observan en el 40-80\% de los pacientes con enfermedad de Pringue-Bourneville. 
Los quistes presentan diámetros superiores a 30 $\mathrm{mm}$ pero, raramente, sobrepasan los $50 \mathrm{~mm}$ en el cortex y la médula y se acompañan de hamartomas. Estos quistes pueden presentar calcificaciones murales y los hamartomas presentan densidades entre -80 y -110 UH debido a los componentes grasos.

\section{La enfermedad de Von Hippel-Lindau}

Es otra enfermedad hereditaria dominante que se manifiesta en la segunda década de la vida y conlleva los siguientes cambios:

1. Quistes renales.

2. Hemangioblastoma cerebeloso.

3. Angiomatosis de la retina.

4. Otras lesiones en distintas partes del cuerpo: páncreas, hígado, adrenales, epidídimo,etc.

\section{La enfermedad de VHP}

Conlleva la posible degeneración a adenocarcinoma renal sin o con degeneración quística previa y es bilateral en el 75\% de los pacientes afectos, multifocal en un riñón en el $87 \%$ de los casos y asociado a feocromocitoma en un $10 \%$.

\section{NEFROMA QUÍSTICO MULTILOCULAR}

El nefroma quístico multilocular (NQML) es una lesión ocupante de espacio, definida por una cápsula gruesa y conteniendo formaciones quísticas de variable tamaño separadas por septos fibrosos. El crecimiento de estas lesiones puede ser importante y el promedio de tamaño se encuentra en niveles superiores a los $90 \mathrm{~mm}$. Los quistes no comunican y están tapizados por un epitelio eosinofilico. Pueden contener líquido claro o material mucoso y proteináceo y el sangrado es raro en este tipo de formaciones. La hematuria puede presentarse por herniación del tumor dentro del sistema colector y puede producirse ulceración.

\section{LESIONES INFLAMATORIAS}

Dentro de las lesiones inflamatorias que se comportan como "masa renal " destaca la Pielonefritis Xantogranulomatosa (PXG). Esta enfermedad inflamatoria crónica y destructiva del parénquima es el producto de una infección bacteriana combinada con un proceso obstructivo, su principal factor predisponerte. El proceso inflamatorio comienza en la pelvis renal y causa una destrucción progresiva de la medular y la corteza renal. La afectación renal es, normalmente, difusa pero pueden presentarse formas focales en cálices obstruidos o en vías excretoras dobles.
Los cálices, frecuentemente, presentan bordes irregulares y se encuentran agrandados pero también pueden resultar comprimidos o englobados por el proceso inflamatorio. El parénquima se reemplaza por un magma amarillento, xantomatoso y se muestran múltiples cavidades necróticas. Histológicamente, el tejido consiste en una reacción inflamatoria crónica con macrófagos cargados de lípidos en forma de células xantomatosas o de patrón “espumoso". La sustitución fibrosa del parénquima se encuentra en las cercanías del cortex y este proceso inflamatorio puede extenderse a los tejidos o estratos vecinos, especialmente al espacio perinéfrico, espacio pararrenal posterior, flanco, espacio pararrenal anterior $\mathrm{y}$ determinar la creación de fístulas.

La TC muestra en el riñón afecto múltiples áreas hipodensas $(-15 \mathrm{a}+20 \mathrm{UH})$ que remedan un patrón hidronefrótico. Estas áreas se corresponden con cálices dilatados o cavidades necróticas. Las unidades Hounsfield negativas se relacionan con el tejido graso y material purulento. Tras la administración de medio de contraste yodado IV existe un fuerte realce debido al anillo inflamatorio periférico o por el parénquima renal comprimido.

Dentro de la PXG difusa, se pueden observar en algunas ocasiones los sistemas colectores masivamente dilatados con atrofia del parénquima y su sustitución por tejido necrótico e infiltrados xantomatosos.

La PXG focal es infrecuente y afecta en mayor proporción a mujeres y niños. Los cambios anatomo-radiológicos son similares a los de la PXG difusa pero limitados a un área. La PXG puede estudiarse en función a los siguientes hallazgos:

PXG grado I. Existen cambios patológicos sólo en el riñón.

PXG grado II. Existen cambios perirrenales.

PXG grado III. Existe una inflamación perinéfrica y cambios inflamatorios.

\section{La Pielonefritis focal aguda o Nefronia lobar}

Se considera como una forma más de una pielonefritis no complicada. El área de infección puede aparecer como una masa. En contraste con los abscesos renales no existe una supuración y, por lo tanto, no es una lesión candidata al drenaje. Este tipo de lesión es un estado preabsceso. En los estudios TC basales, el riñón puede aparecer normal o débilmente hipodenso en el área afecta y, en estudios con contraste yodado IV se exhiben áreas hipo- 
densas redondeadas con ausencia de realce o realce tenue. Estos hallazgos pueden regresar a la normalidad o progresar a otras formas más complejas, especialmente en paciente inmunodeprimidos.

\section{Los abscesos intrarrenales}

Están causados frecuentemente por infecciones ascendentes de organismos Gram (-). Se desarrollan muchos microabscesos en el curso de una pielonefritis aguda y estos focos pueden, eventualmente, originar una gran cavidad de absceso. La infecciones hematógenas por gérmenes Gram(+) han disminuído su incidencia por la antibioterapia.

Factores predisponentes son las obstrucciones urinarias (se presentan cálculos en el 25\% de los casos), la diabetes mellitus, caquexia, abuso de drogas o estados de inmunosupresión. Los abscesos múltiples se observan en casos de urosepsis. En estos casos se pueden observar un abombamiento del contorno renal, un incremento de tamaño del órgano y franca asimetría con el contralateral, en dependencia del tamaño de la lesión.

Después de la administración de medio de contraste yodado se pueden observar lesiones fuertemente delimitadas con densidades entre 0-20-30 UH. $\mathrm{El}$ realce periférico se debe a la perfusión de los vasos dilatados que rodean la lesión o por el tejido de granulación inflamatorio. En las lesiones periféricas se pueden observar engrosamientos de la fascia de Gerota o de la lateroconal y estriaciones de los planos grasos perinéfricos. La extensión de los abscesos puede determinar cambios en el espacio perirrenal y pararrenal o en el compartimento del psoas.

\section{Los abscesos pararrenales}

Pueden desarrollarse por extensión directa desde los procesos inflamatorios perirrenales o derivar de otros procesos como la enfermedad de Crohn, diverticulitis, osteomielitis costo-vertebral o infecciones ascendentes desde el área sigmoidea.

Las pionefrosis representan colecciones de pus en sistemas colectores dilatados en combinación con una disminución de la función renal. Si únicamente, existe una cáliz afectado, se denominada piocaliz. Los pacientes tienen una sintomatología de fiebre, dolor en flanco, escalofríos y episodios afebriles. La terapéutica, en estos casos, es efectuar un drenaje percutáneo bajo cobertura antibioterápica. La TAC muestra sistemas colectores dilatados, en dependencia del nivel de obstrucción y con densidades del líquido infectado entre 20-30 UH o más.

\section{TUMORES RENALES}

Los tumores renales no son frecuentes. Representan, únicamente, el $2 \%$ de los tumores del adulto. El $90 \%$ de los tumores renales son carcinomas de células renales y su pico de incidencia se encuentra entre los 50 y los 70 años de edad y el varón duplica en frecuencia a la mujer. No obstante, el riñón es lugar de desarrollo de una gran variedad de enfermedades neoplásicas y se presentan formas de comportamiento benigno y maligno.

\section{El adenoma renal}

Se constata en un 15\% de autopsias. Se presenta como un tumor único o múltiple subcapsular, normalmente, con diámetro inferior a $10 \mathrm{~mm}$ y su histopatología se basa en células basofílicas y con patrones arquitecturales papilares o tubulares. Las lesiones inferiores a $30 \mathrm{~mm}$ pueden ser clasificadas como benignas y las que superan estos parámetros como probablemente malignas.

En cualquiera de los modos diagnósticos por imagen, los hallazgos no son específicos para adenoma. Puede que la masa sea avascular, hipovascular o hipervascular. Un factor a tener en cuenta para sopesar la existencia de un adenoma son los pacientes sometidos a diálisis, los cuales, desarrollan con frecuencia adenomas renales y deben ser sometidos a seguimiento. Si estos tumores incrementan su tamaño, aproximadamente $0,5 \mathrm{~cm} /$ año con un rango entre $0-1,6 \mathrm{~cm} /$ año o se complican con hematuria, deben ser sometidos a cirugía de exéresis.

Los adenomas renales están formados por células uniformes de pequeño tamaño y escaso citoplasma. Su patrón arquitectural es de tipo tubular o papilar y pueden ser muy compactos o con algunas formaciones quísticas $\mathrm{y}$, a pesar de estar bien circunscritos, no están encapsulados.

\section{Los oncocitomas}

Se caracterizan histológicamente por la presencia de oncocitos, células eosinófilas de gran tamaño y con megalomitocondrias. Los oncocitomas representan entre un $1-14 \%$ de los tumores renales encontrados en autopsias. A la visión macroscópica son de contornos suaves, morfología esférica y, con frecuencia, presentan una cicatriz central. La compresión del tejido renal circundante puede proporcionar una visión de pseudocápsula. El oncocitoma no suele presentar hemorragia, necrosis o patrones infiltrativos. La tumoración suele ser asintomática y 
su descubrimiento de tipo incidental aunque, en ocasiones, los pacientes pueden presentar dolor en el flanco, masa en flanco o hematuria. su tamaño varía entre escasos centímetros y $25 \mathrm{~cm}$. La TAC sin y con medio de contraste yodado IV. aporta importantes datos en la caracterización de este tipo de masa renal. La presencia de una cicatriz central dentro de una lesión sólida y homogénea, el realce del área cicatricial por tejido fibrosos vascularizado, el realce homogéneo de la masa y la ausencia de calcificaciones aportan los principales parámetros para el diagnóstico de oncocitoma, (Figs. 1a, b, c y d).

Microscópicamente, las células se disponen en nidos de tipo alveolar, trabéculas o formaciones tubulares separadas por un estruma laxo edematoso. El patrón inmunohistoquímico está dominado por una ausencia de reacción a vicentina y ci-
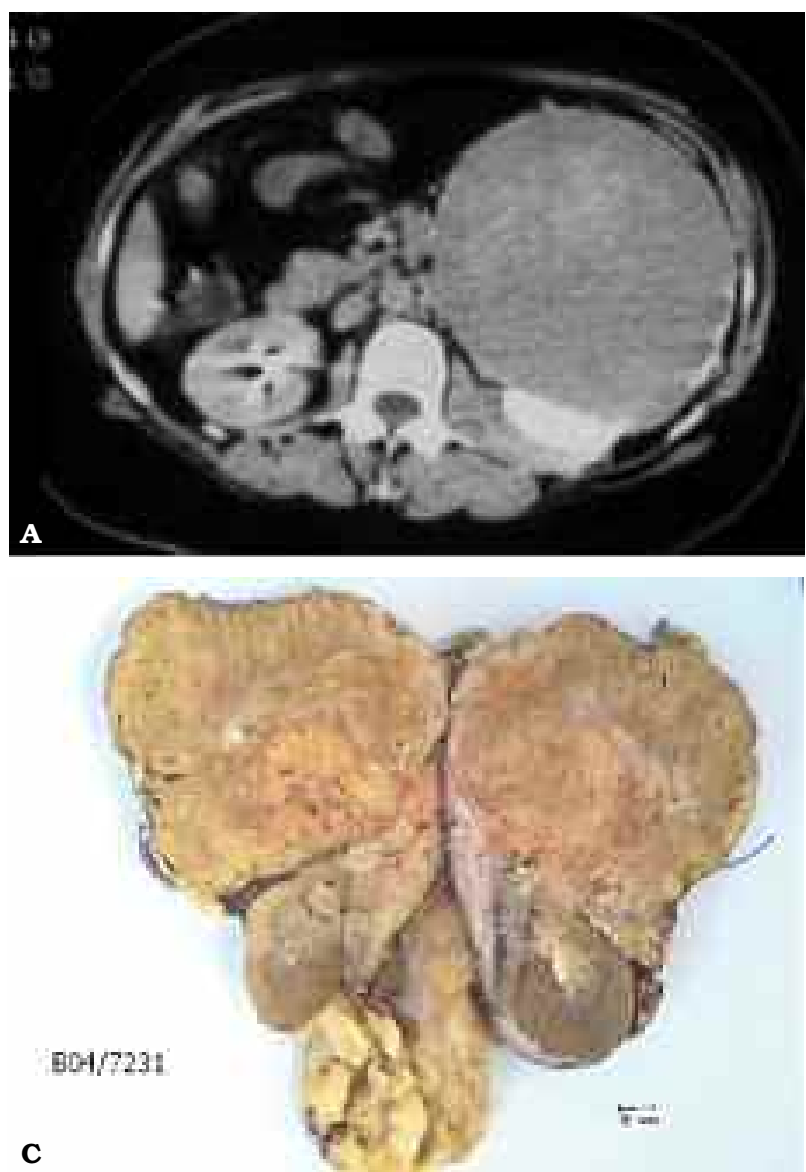

toqueratina $7 \mathrm{y}$, por el contrario, muestran positividad a las citoqueratinas 8 y 18, y esto, permite su diferenciación con el tumor de células granulares.

\section{El adenoma metanefógeno}

Es un adenoma especial. En modos de imagen (TC y RMI) pueden exhibir distintos patrones de realce al medio de contraste yodado IV y paramagnético. No presentan patrones de infiltración y es inusual la necrosis o la calcificación.

\section{E1 angiolipoma}

Representa otra masa renal de características histológicas benignas. Puede presentarse como una lesión única o múltiple, uni o bilateral y en relación con enfermedades más complejas como la esclerosis tuberosa de Bourneville. Esta última presentación conlleva la existencia de múltiples y pequeños tumo-
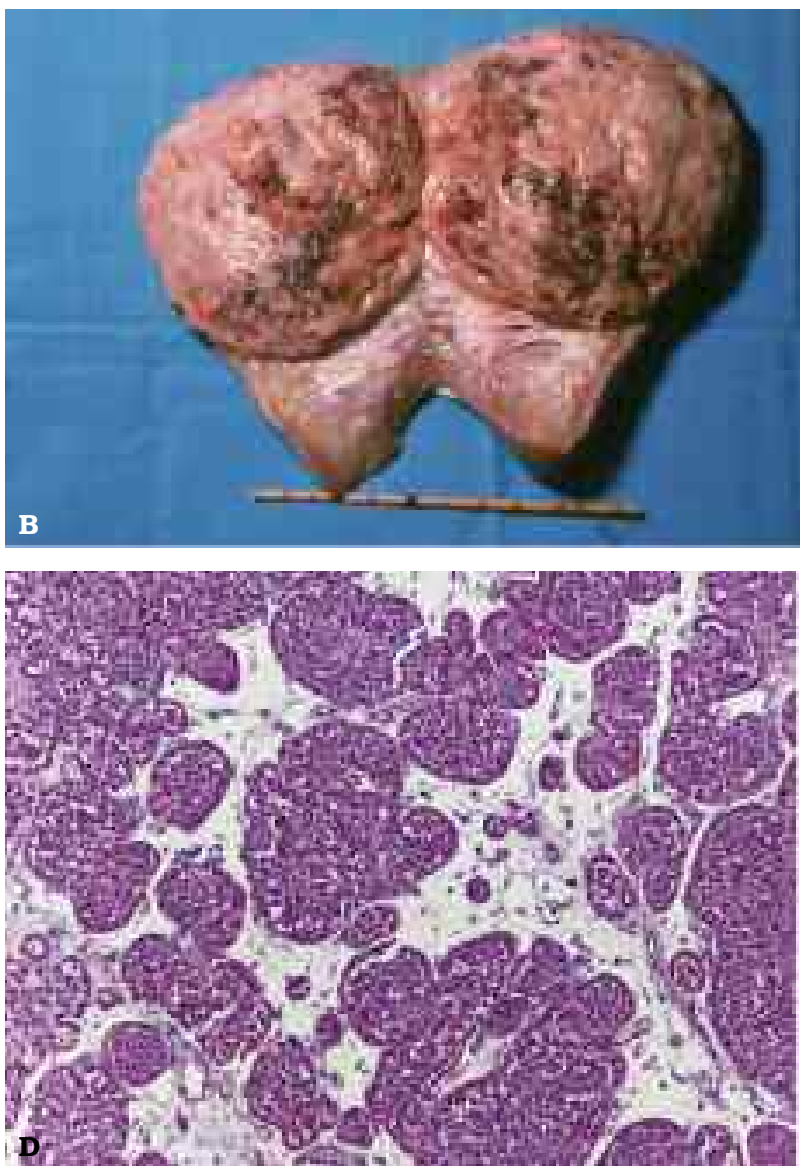

FIGURA 1. A). TC renal mostrando una gran tumoración de densidad homogénea no capsulada y con realce escaso y difuso en su 1/3 anterior. La masa presenta una buena definición con el parénquima adyacente. B) Pieza macroscópica del tumor evidenciando la ausencia de necrosis, calcificación, definición neta con el riñon sano y coloración rosácea intermedia caracterizando un ONCOCITOMA. C) Imagen macroscópica de un ONCOCITOMA mostrando su zona central estrellada y un patrón arquitectural en "rueda de carro" . Los contornos se pueden presentar lisos o levemente lobulados.

D) Imagen microscópica de un ONCOCITOMA mostrando su arquitectura compacta en "archipiélago", con citoplasma eosinófilo y rico en mitocondrias. 
res en pacientes jóvenes. Los angiomiolipomas solitarios, de gran diámetro y unilaterales predominan en la mujer de edad media. Si la tumoración es voluminosa pueden existir cambios de necrosis o hemorragia en su interior y, raramente, calcifican.

\section{Los angiomiolipomas (AML)}

Se caracterizan histológicamente por presentar tejido graso en proporciones variables, músculo liso y vasos, es decir, tienen una estructura de hamartoma, tejidos de características histológicas normales en localización y proporciones anormales, lo que le da un aspecto en imágenes TC de "área de fumadores" al intercalarse en la atmósfera grasa elementos de mayor densidad en forma de estriaciones, representando a fibras musculares y vasos. (Figs. 2a y b).
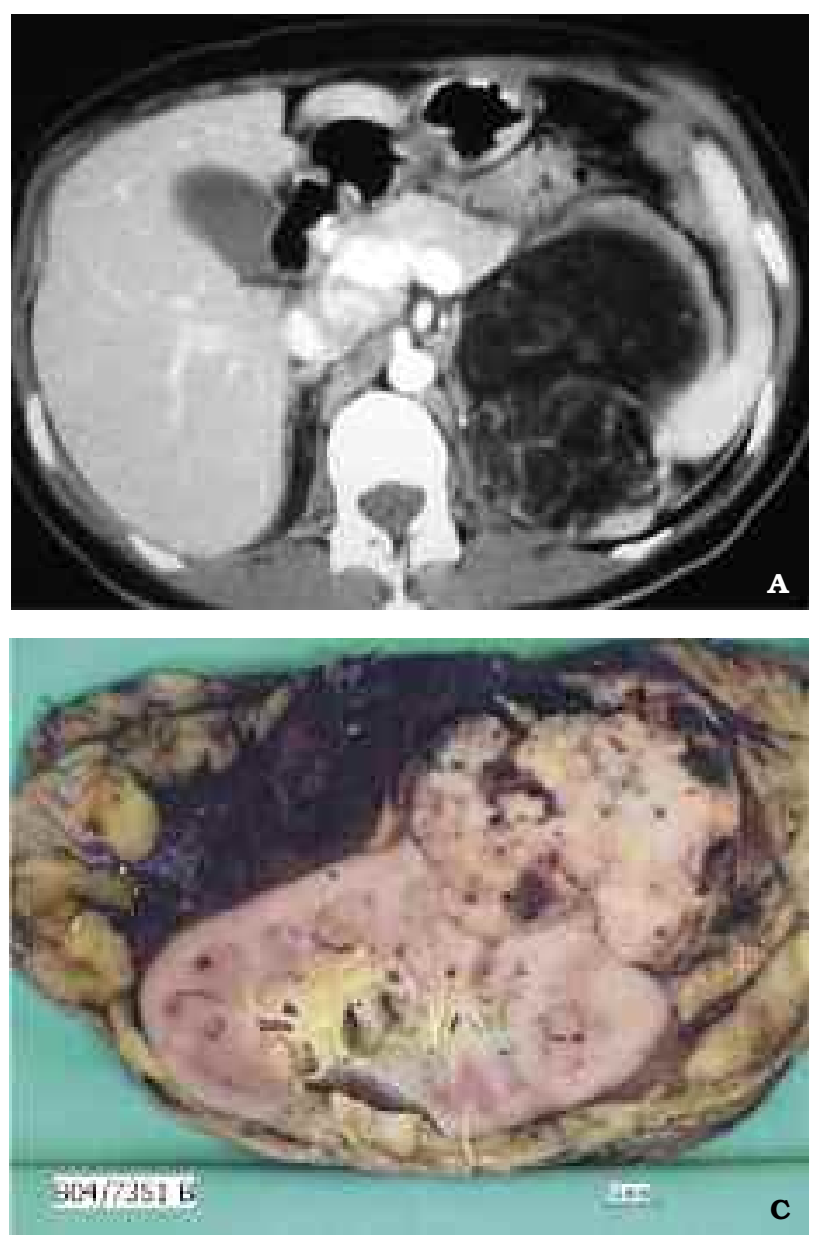

Los pacientes pueden tener dolor en flanco, efecto de masa palpable, hematuria, anemia o ser asintomáticos. La hemorragia debido a rotura post-traumática o a hipertensión son una de las complicaciones más significativas de esta entidad.

\section{Los AML's}

Son, fundamentalmente, lesiones hipodensas con valores de atenuación TC entre los -40 y los -120 UH. Para detectar la presencia de acúmulos de tejido graso es preciso realizar cortes TC de 4-5 mm y sin realce por medio de contraste yodado IV. Después de la administración de medio de contraste yodado puede no existir realce, en proporción al acúmulo de grasa y la minorización del patrón de vasos o, por el contrario, evidenciar paquetes importantes vasculares o contenidos fibromusculares relevantes (Figs. 2c y d).
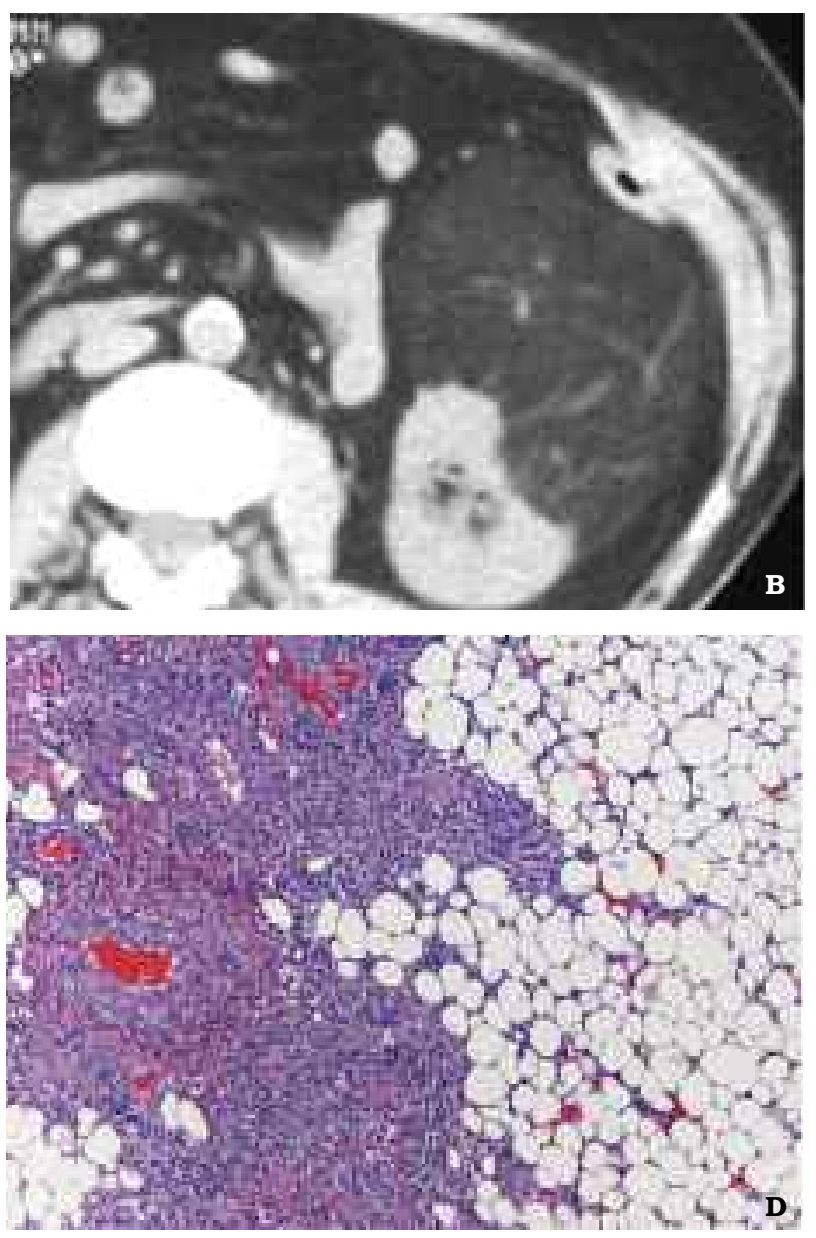

FIGURA 2. A y B) mostrando en imagen TC la existencia de dos masas capsulo-subcapsulares con arquitectura predominante grasa (densidades negativas entre -190 y -110 U.H.) En el seno de ambas masas se delinean estructuras vasculares y elementos de densidad intermedia caracterizando ANGIOMIOLIPOMAS renales izquierdos. Imagen macroscópica (C) y Microscópica (D) en ANGIOMIOLIPOMA. Su caracterización se basa en la proporción de sus componentes tisulares. Su color es, generalmente, amarillento. Es un tumor no capsulado pero muy bien delimitado. No presenta atipias. 


\section{El carcinoma renal}

Como tumor epitelial maligno del parénquima renal. Se le clasifica en función del tipo celular (de células grandes, de células fusiformes, de células claras) y del patrón arquitectural o de crecimiento (acinar, papilar o sarcomatoide). La introducción de conocimientos genéticos ha cambiado el concepto básico de esta patología y la clasificación de Heidelberg, mezcla de patrones genéticos y hallazgos morfológicos, son una buena expresión de ello.

\section{El adenocarcionma renal de células claras}

Representa el 90\% de todos los tumores renales. $\mathrm{Su}$ incidencia pico se encuentra entre los 50 y 70 años, afecta al doble de varones que a hembras y su incidencia se incrementa en la enfermedad de Von Hippel-Lindau, la esclerosis tuberosa de PringueBourneville y en pacientes con diálisis.

El conocimiento exhaustivo de la morfología, histología, histoquímica, inmunología y ultraestructura del carcinoma de células renales (CCR) y su diversidad de características morfoestructurales hace que los clínicos posean una mejor comprensión del pronóstico y su significación con estos parámetros, estadio y grado nuclear.

Las neoplasias renales demuestran una considerable variación de las velocidades de crecimiento (rangos de 0 a 1,6 cm/año), tomadas desde mediciones lineales en el máximo rango diametral axial. La desviación estandar se estima en $\pm 2 \mathrm{~mm}$ y el espesor de corte de referencia es de $5 \mathrm{~mm}$. Los cambios relativos de tamaño se deben observar en períodos superiores a 2 años. Una neoplasia que dobla su diámetro de 1,0 a $2,0 \mathrm{~cm}$ puede incrementar su volumen desde 0,52 a 4,19 $\mathrm{cm}^{3}$, asumiendo un modelo esférico de crecimiento igual a $\mathrm{V}=4 / 3 \pi \mathrm{r} 3$.

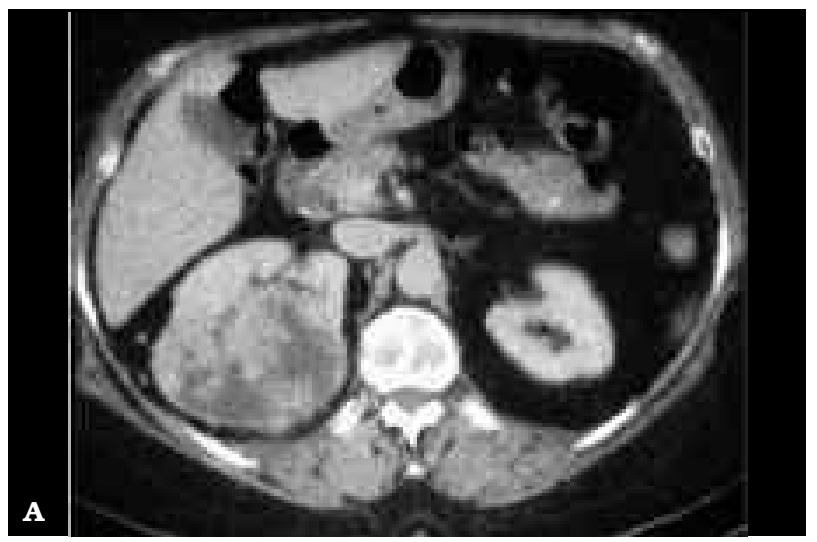

Las neoplasias de bajo grado y bien diferenciadas aparecen, fundamentalmente, como homogéneas, bien marginadas en comparación con otras más heterogéneas de los tumores peor diferenciados. El grado tumoral y la resistencia del huésped son los determinantes últimos para la velocidad de crecimiento de estas neoplasias.

La definición de adenoma estuvo basada, en su tiempo, en solo el parámetro de tamaño. El Carcinoma de células renales no es distinguible del adenoma renal y su relación diagnóstica para adenoma está basada en la escasa o nula velocidad de crecimiento y ausencia de metástasis. Los carcinomas de células renales tienen unos rangos lineales de crecimiento de 3,5 a 7,0 $\mathrm{cm}$ en tumores diagnosticados con $3 \mathrm{~cm}$ de diámetro máximo y un rango de crecimiento de 0,5 a 4,0 $\mathrm{cm} /$ año. Otros factores que se consideran están relacionados son las resistencias del huésped. El tumor puede crecer con extremada lentitud en períodos muy dilatados de tiempo, parar su crecimiento o iniciar síntomas de remisión, lo que se ha denominado "carcinoma de células renales semicongelado".

Microscópicamente, los carcinomas de células renales son de arquitectura heterogénea; muestran áreas de hemorragia, necrosis y cambios quísticos secundarios, fibrosis y calcificación. El adenocarcinoma papilar tiene un crecimiento rápido y tienen una alta incidencia de componentes quísticos. Estos tumores tienen bordes definidos en relación al parénquima renal debido a la pseucápsula creada por la compresión del parénquima adyacente y la reacción fibrótica provocada por su crecimiento. Todas estas características macroscópicas tienen su representación en los distintos modos de diagnóstico por imagen (Figs. 3a y b).

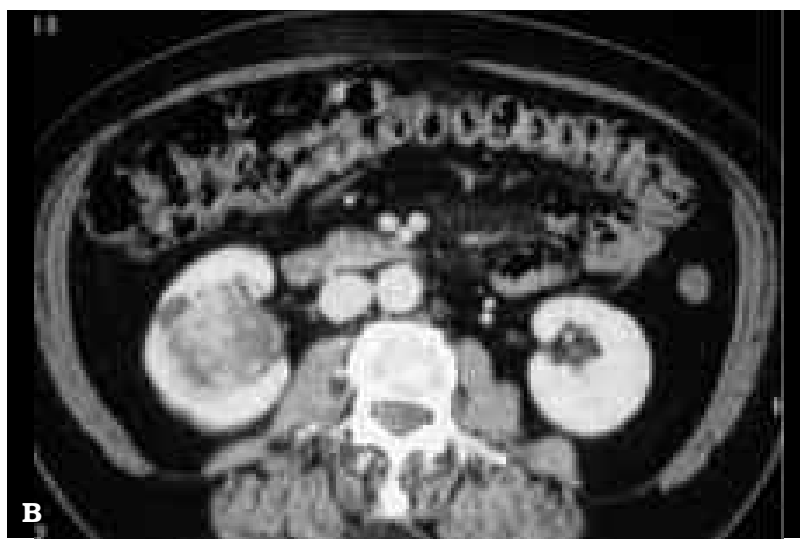

FIGURA 3. A y B) Imágenes TC con medio de contraste yodado i.v. mostrando sendas masas en riñón derecho. (A) en 1/3 supe rior y medio posterior del $R D$ y (B) de ocupación hiliar en $R D$. Ambas masas exhiben realces heterogeneos, inferior al del parénquima renal y muestran áreas hipodensas de necrosis. 
Los carcinomas de células renales se originan de las células tubulares proximales y se clasifican de acuerdo a su tipo celular, características del crecimiento y criterios citológicos. La variedad celular más frecuente es la de células claras (71\%), seguida de la de células cromófobas (15\%) (Figs. 3c, d, e y f).

Para diferenciar los subtipos histológicos, el patrón de realce en TC es el parámetro más útil. El de células claras es el que presenta el mayor grado de realce y puede ser heterogéneo en base a la presencia de áreas necróticas o quísticas. El CCR claras muestra realces superiores a $85 \mathrm{UH}$ en la fase de diferenciación cortico-medular, mientras que, el carcinoma papilar es, típicamente, hipovascular y con realce periférico. El subtipo cromófobo muestra un realce moderado y homogéneo y tiene un comportamiento radiológico similar a los oncocitomas. El carcinoma de células renales quístico multilocular es un tumor de comportamiento benigno y muestra septos que separan cámaras de tamaños variables y muestra cápsula (Figs. 4a y b) (Figs. 4c y d).

La hemorragia perirrenal es una forma de presentación atípica del CCR y no guarda relación con el tamaño del tumor y la TC es un modo diagnóstico básico para su determinación, con una sensibilidad del 100\%. La TC es el método de elección para el diagnóstico de los tumores renales. Su sensibilidad en el diagnóstico de tumor es del $94 \%$ y la fiabilidad en el estadiaje se encuentra en el 90\%, algunas veces en inferioridad a la RMI. (Figs. $4 \mathrm{e}$ y f).

Las principales preguntas que nos debemos hacer son las siguientes: ¿Existe un tumor renal?. Si existe, ¿Es benigno o maligno?. ¿Presenta crecimiento más allá del riñón? ¿Se encuentran afectadas las cadenas linfáticas? ¿ Existen metástasis a distancia? ¿El sistema colector está infiltrado por el proceso tumoral ? ¿La grasa perinéfrica está infiltrada? \& Hay trombo tumoral en vena renal o VCI? Todas estas cuestiones deben reflejarse en el estadiaje de la tumoración renal.

Los carcinomas de células renales provocan cambios en el contorno, la forma y la orientación del órgano en dependencia de su volumen y localización. La tumoración, en TC basal puede ser hipodensa, isodensa o hiperdensa en relación al parénquima adyacente. Las áreas hiperdensas se suelen correlacionar con focos de hemorragia intratumoral. Las áreas quísticas o tumores quísticos se encuentran relacionados con las formas papilares del cáncer renal.
Las calcificaciones se identifican netamente en TC. En la mayor parte de los casos son amorfas y centrales y se agrupan en "cluster". Las que presentan morfología en "cáscara de huevo" se asocian a pequeños tumores.

Después de la administración de medio de contraste yodado en forma de "bolus", la mayor parte de los tumores experimentan realce en los tiempos más tardíos de la fase parenquimatosa. El parénquima renal adyacente suele realzar en un grado superior $\mathrm{y}$ se establece un contraste neto entre órgano y tumor. Las áreas necróticas no experimentan realce después de la administración de medio de contraste. La borrosidad de los contornos renales se asocia con infiltración perinéfrica (Figs. 5a y b).

La TC presenta una sensibilidad entre el 78 y el $95 \%$ en detectar trombo tumoral y muestra una especificidad del 96\%. El trombo se observa como un defecto de relleno o como un tumor vascular después de la inyección en "bolus" de medio de contraste debido a la arterialización del trombo en el interior de la vena renal o VCI. Los trombos en la vena renal derecha son más difíciles de evaluar debido a su cortedad y oblicuidad y, en casos de obstrucción del flujo hepático venoso a la VCI por la acción de un trombo tumoral, se puede presentar un síndrome de Budd-Chiari.

\section{ESTADIFICACIÓN DEL CARCINOMA DE CÉLULAS RENALES}

Los principales factores que afectan al pronóstico en el Carcinoma de células renales son:

- El grado nuclear, el subtipo histológico

- La extensión anatómica.

Actualmente, se contemplan diez subtipos histológicos en CCR:

1) Células claras, con origen en los túmulos contorneados proximales.

2) Papilar, con origen en los túbulos contorneados proximales.

3) Cromófobo, en los túmulos colectores corticales.

4) Quístico multilocular.

5) Carcinoma de túmulos colectores, con origen en los túmulos colectores medulares.

6) Carcinoma tubular mucinoso, en asa de Henle.

7) CCR asociado a neuroblastoma.

8) Carcinoma de traslocación.

9) Síndromes de carácter hereditario y

10) Lesiones no clasificables. 

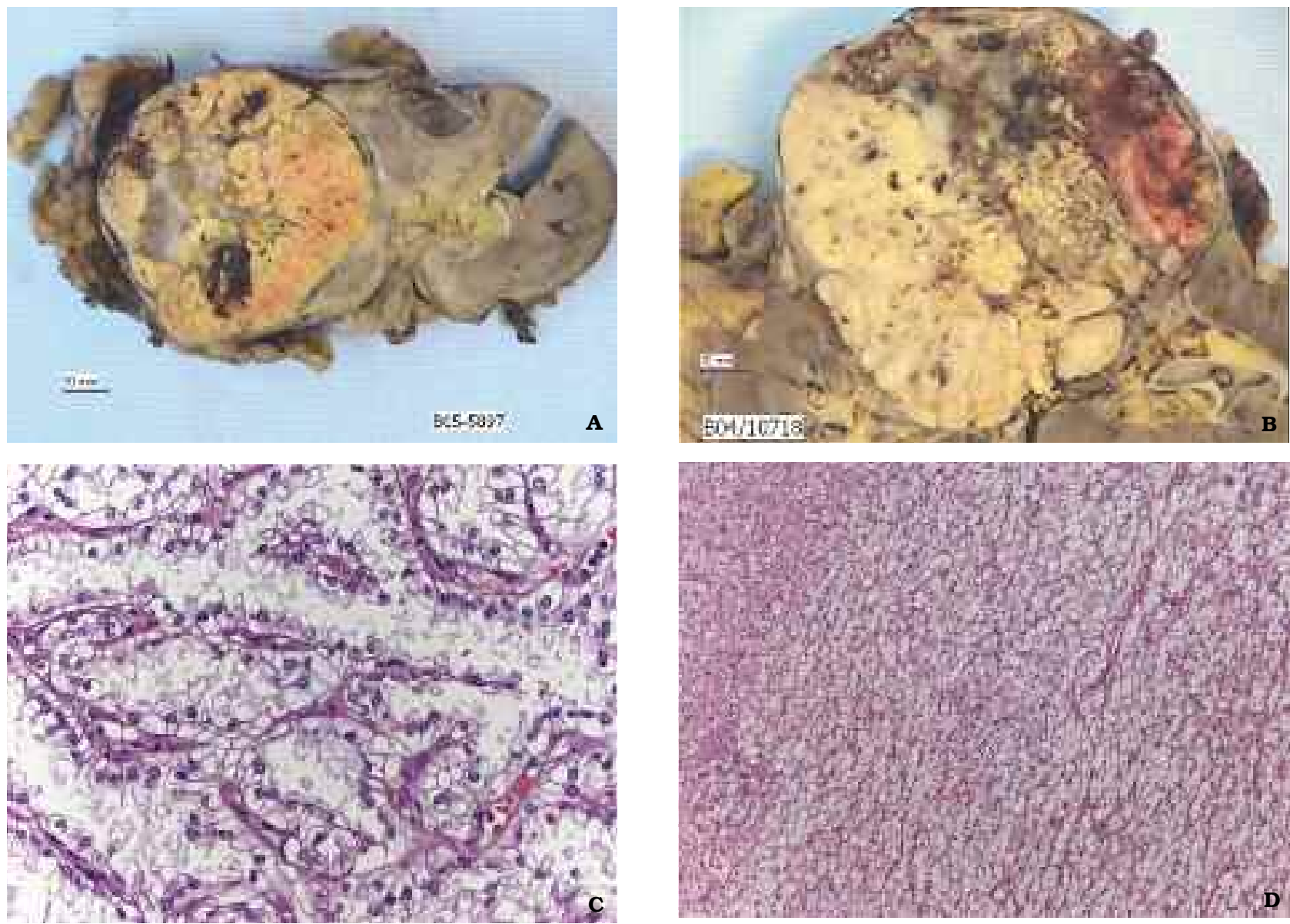

FIGURAS 3 C Y D) IMÁGENES MACROSCÓPICAS DE CARCINOMA DE CÉLULAS RENALES CLARAS. Su coloración puede SET anaranjada clara $y$ muestra, frecuentemente, áreas de hemorragia y necrosis con bordes infiltrativos. En ocasiones se pueden observar en su interior áreas quisticas. E) Imagen microscópica en CCR claras con citoplasma espumoso o eosinofilico granular. La arquitectura vascular es delicada y presenta compacidad tubulo-quística. El CCR se grada según la clasificación de Furhrman. Establece 4 grados en relación a criterios nucleares, presencia o no de nucleolo, tamaño y contorno. CCR G1 con núcleo de $10 \mu \mathrm{m}$ sin nucleolo.

El factor individual pronóstico más importante, en relación con cualquiera de los subtipos histológicos expresados, es la extensión anatómica del tumor en el momento del diagnóstico. El progreso en las técnicas quirúrgicas avala que la cirugía conservadora se puede realizar con éxito en pacientes con tumores limitados al riñón, monorrenos, con insuficiencia renal o con tumores múltiples bilaterales.

La TC es la técnica diagnóstica de primera elección para la estadificación del cáncer renal con una fiabilidad del 91\%, aunque, los estudios de RMI pueden, en especiales circunstancias, ayudar a precisar elementos de interés en el proceso: (a) visualización de la integridad de la pseudocápsula en las formas de CCR papilar; (b) visualización del trombo tumoral en las venas renales, VCI y su extensión; (c) alteración de la señal en la grasa perinéfrica en caso de infiltración y (d) valoración linfática y metastásica. El protocolo de examen TC incluye un estudio basal, con medio de contraste en fases (1) cortico-medular; (2) nefrográfica; (3) excretora con reconstrucciones multiplanares. (Figs. 6a, b, c y d).

La invasión de la grasa perirrenal es determinante para establecer la técnica quirúrgica a emplear. La afectación del compartimento perinéfrica indica nefrectomía radical. La aseveración mediante métodos de imagen de la afectación de la grasa es una fuente importante de falsos positivos y negativos. La presencia de nodulaciones con realce en el seno de la grasa es un dato más específico pero puede deberse a cambios no tumorales por ingurgitación vascular o edema si hubiera existido inflamación previa. (Figs. $7 \mathrm{a}$ y b). 

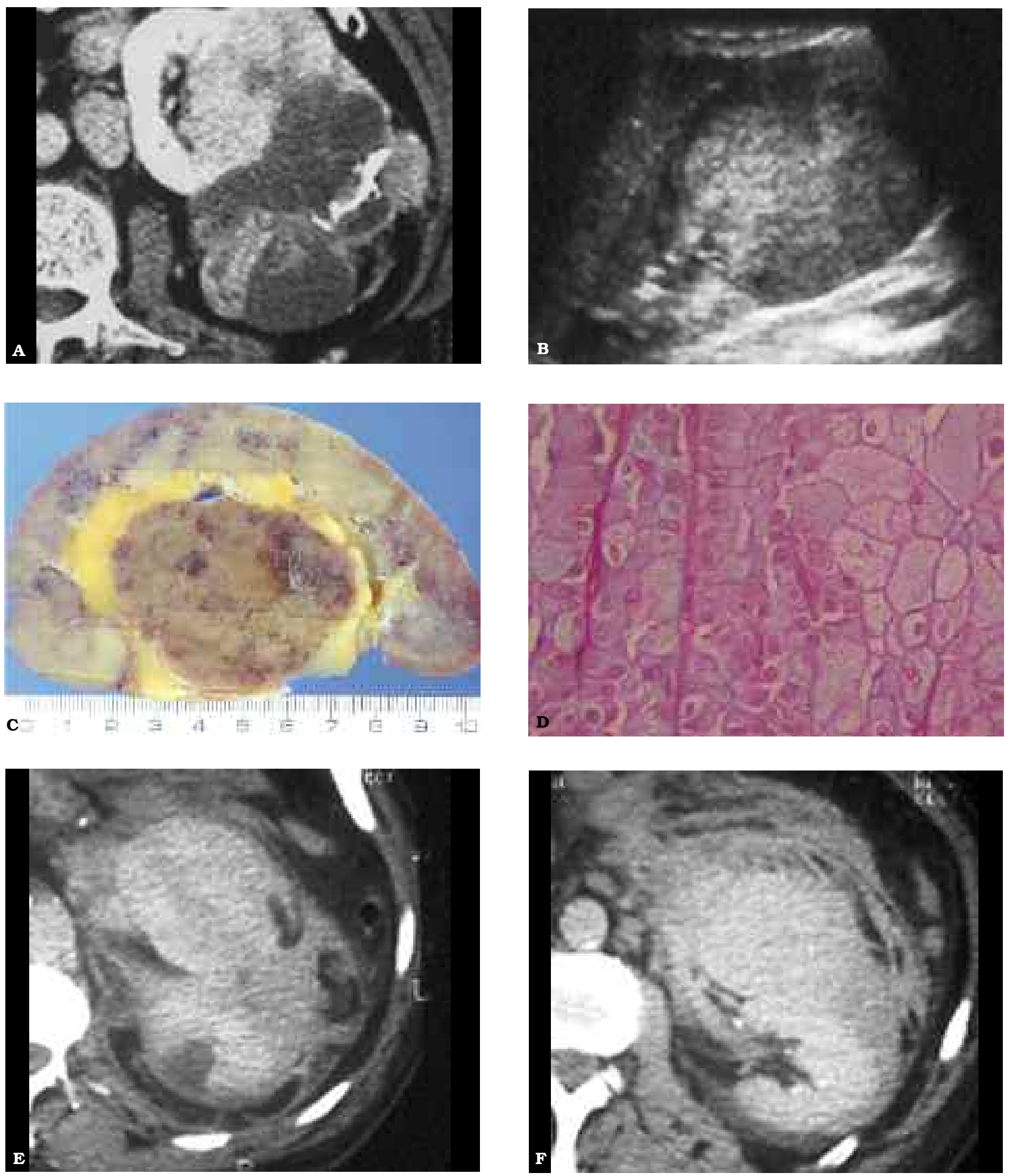

FIGURA 4. A) Imagen TC con medio de contraste yodado i.v mostrando una tumoración renal izquierda que muestra: (1) patrón infiltrativo del parénquima, (2) áreas necróticas y (3) placas de calcio distrófico en los bordes necróticos. Adenocarcinoma de células claras R.I.. Adenopatías hiliares. B) Masa renal derecha polar inferior. Exploración ultrasonográfica. Ecoarquitectura homogenea, fuertemente ecogénica, sin áreas de necrosis, similar a la arquitectura del oncocitoma. C) Pieza macroscópica de Adenocarcinoma Cromófobo. Representa un $5 \%$ de los tumores epiteliales, es sólido, bien circunscrito y de un color grisaceo variable. D). Imagen microscópica de un adenocarcinoma cromófobo. Patrón sólido, citoplasma eosinófilo y halo perinuclear. $\mathrm{E}$ y F) Mostrando sangrados tumorales y comportamiento como hemorragia renal, subcapsular, capsular y perinéfrica. Efecto masa y densidades heterogeneas debido a la concentración hemática y férrica y retracción de coágulo y fracción de suero. 

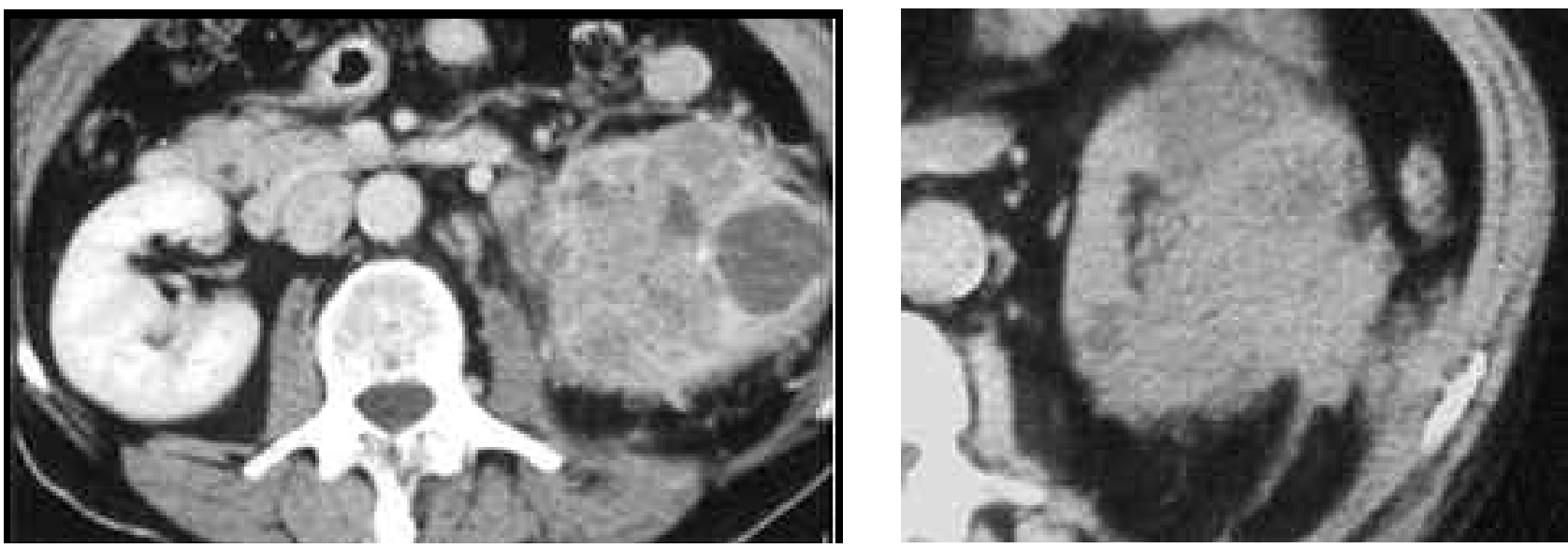

FIGURA 5 A) Imagen TC mostrando una tumoracion renal izquierda con extensión perinéfrica (engrosamiento de septos perirrenales) y presencia de vasos venosos perinéfricos. Areas necróticas y quisticas internas. Realce vascular moderado-intermedio del tejido tumoral. B) Extensión tumoral más allá de la cápsula. Imágenes de infiltración perinéfrica, fascial y del flanco izquierdo.

El Estudio de los Gánglios Linfáticos regionales, bien mediante TC, bien por RMI y la utilización de medios de contraste en base a nanoparticulas de óxido de hierro (USPIO) es determinante para el establecimiento de un pronóstico. La afectación metastásica de los ganglios linfáticos indica mal pronóstico y una supervivencia a 5 años del 5-30\% de los pacientes. El diagnóstico de invasión ganglionar está basado en criterios de tamaño. La TC y RM presentan una fiabilidad entre el 83 y $88 \%$. La PET-TCFDG tiene una sensibilidad del $85 \%$ y una especificidad del $100 \%$. La utilización de contrastes de óxido de hierro están demostrando una mayor especificidad para la RM. Este tipo de linfografía se basa en la fagocitación de estas nanopartículas por células del SRE. Un nodo linfático normal disminuirá su señal en forma homogénea por los efectos ferromagnéticos + del contraste. Por el contrario, un nodo linfático afectado, parcial o totalmente, exhibirá una alta intensidad de señal al no presentar células SRE sino tumorales, (Figs. 8a y b).
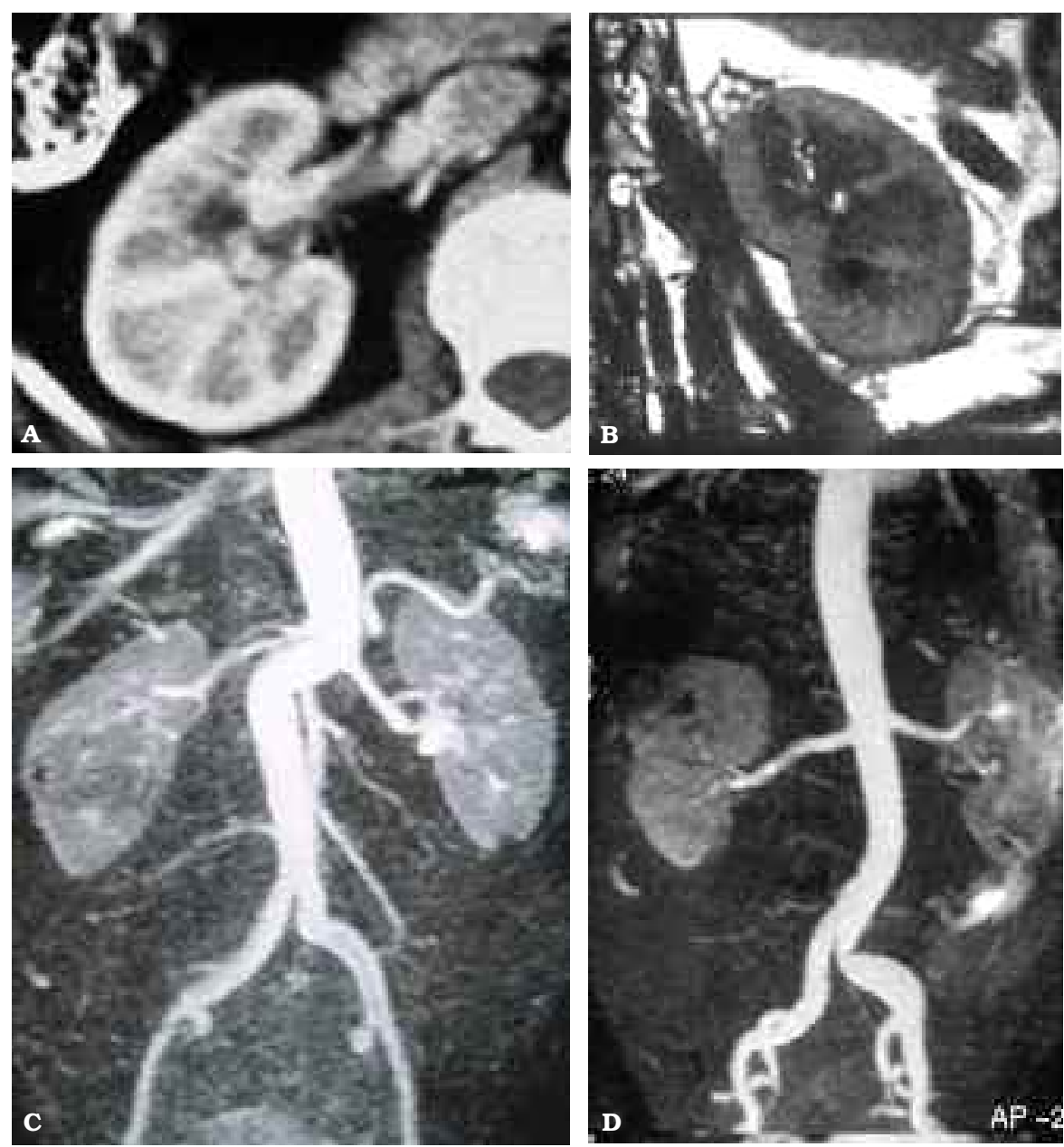

FIGURA 6. A y B) Imágenes básicas TC y RM para estudio de la arquitectura renal, morfología, volumen, entorno y estado de las vías excretoras. La imagen TC con medio de contraste yodado $\mathrm{IV}$ nos ofrece una imagen nitida de la diferenciación cortico-medular, del área hiliar y retroperitoneal. La imagen $R M$ en secuencias potenciadas T1 permite estudiar el órgano en todos los planos y ofrece una diferenciación cortico-medular sin contraste. $C$ y D) Reconstrucciones MIP (maximum intensity projections) en Angio - RMI aorto-renal. Valoración pre-quirúrgica de la vascularización renal, tumoral y retroperitoneal en búsqueda de anomalias, vasos accesorios y redes de suplencia anormales. 

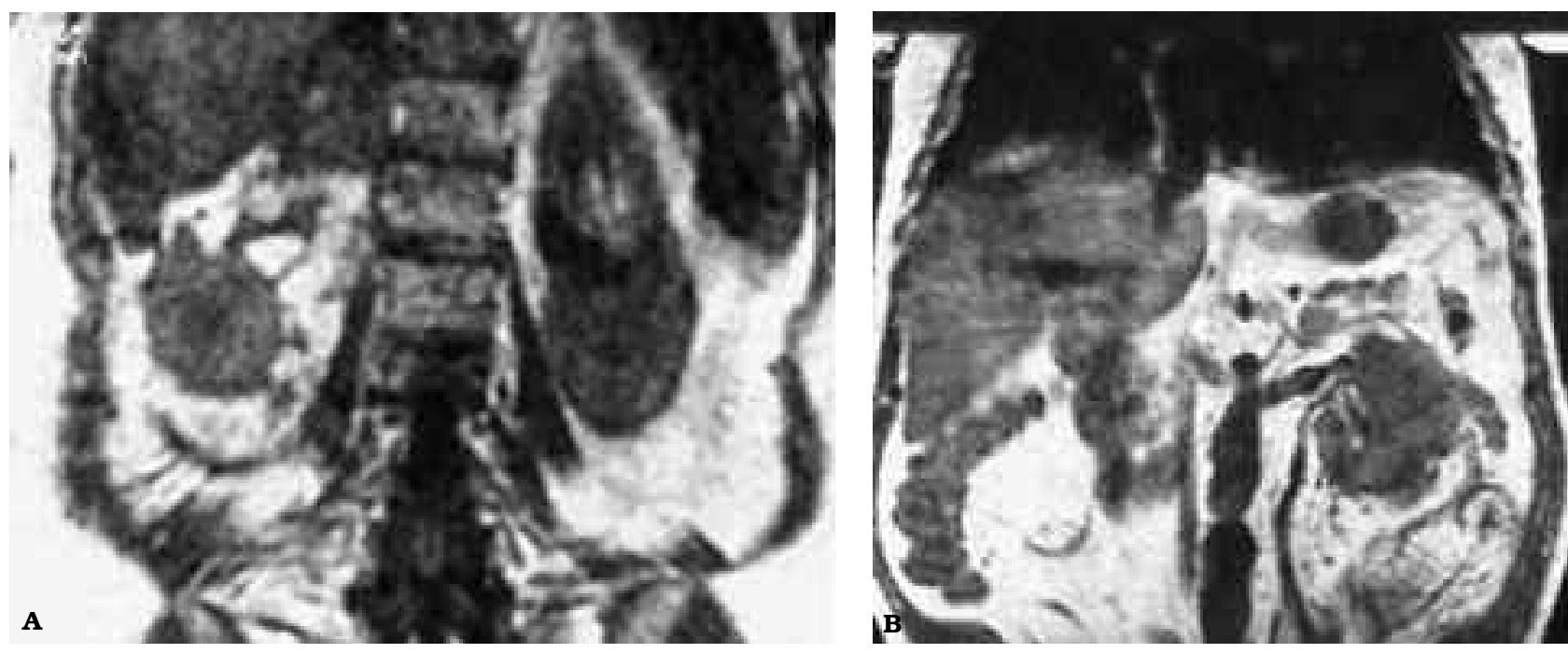

FIGURA 7. A y B) Imágenes RMI en plano coronal y secuencias basales potenciadas T1 mostrando una afectación perinéfrica derecha izquierda. Se evidencia el engrosamiento de los septos perirrenales, la presencia de vasos venosos y la afectación fascial renal. La grasa perirrenal se muestra rarefacta en señal RM.

La Invasión se estudia mejor con técnicas de RMI. Diferencia trombo tumoral de no tumoral. El trombo tumoral es heterogéneo, hiperintenso en secuencias potenciadas $\mathrm{T} 2$ y se realza con medio de contraste. El trombo no tumoral es hipointenso por la concentración de hierro hemático, es homogéneo y no realza (Figs. 9a, b y c).

La invasión adrenal puede ser sincrónica e ipsilateral. La TC tiene un VPN del 100\% y un VPP del $92,8 \%$. La extensión directa del tumor fuera de la fascia de Gerota hacia los órganos vecinos se estu- dia con más fiabilidad mediante técnicas de RMI. La perdida de los planos grasos con los órganos de vecindad sugiere infiltración directa.

En el momento de la presentación del tumor renal, entre un 25 y un 30\% de los pacientes presentan metástasis isocrónicas. La TC debe incluir en estadificación los campos pulmonares, el hígado, las adrenales y el retroperitoneo (Figs. 10a y b).

\section{RIÑÓN Y LINFOMA}

La afectación primaria renal por linfoma es muy rara. La afectación secundaria, especialmente en
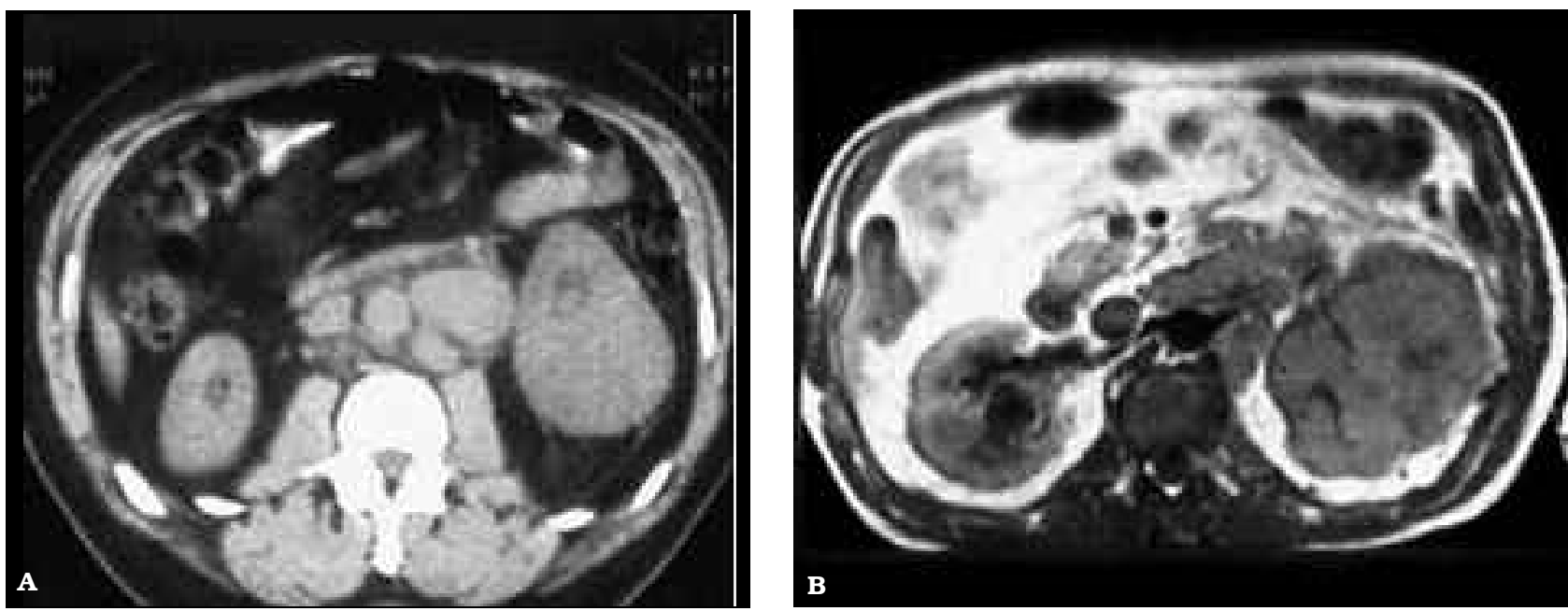

FIGURA 8. A) Imagen TC mostrando una tumoración renal polar inferior izquierda con afectación nodal linfática retroperitoneal. Las linfadenopatias presentan volúmenes variables y la grasa extranodal retroperitoneal se encuentra incrementada de densidad y con finas estriaciones caracterizando una actividad extranodal neoplástica. B) Imagen RMI evidenciando una tumoración renal izquierda con extensión perinéfrica y linfática. 

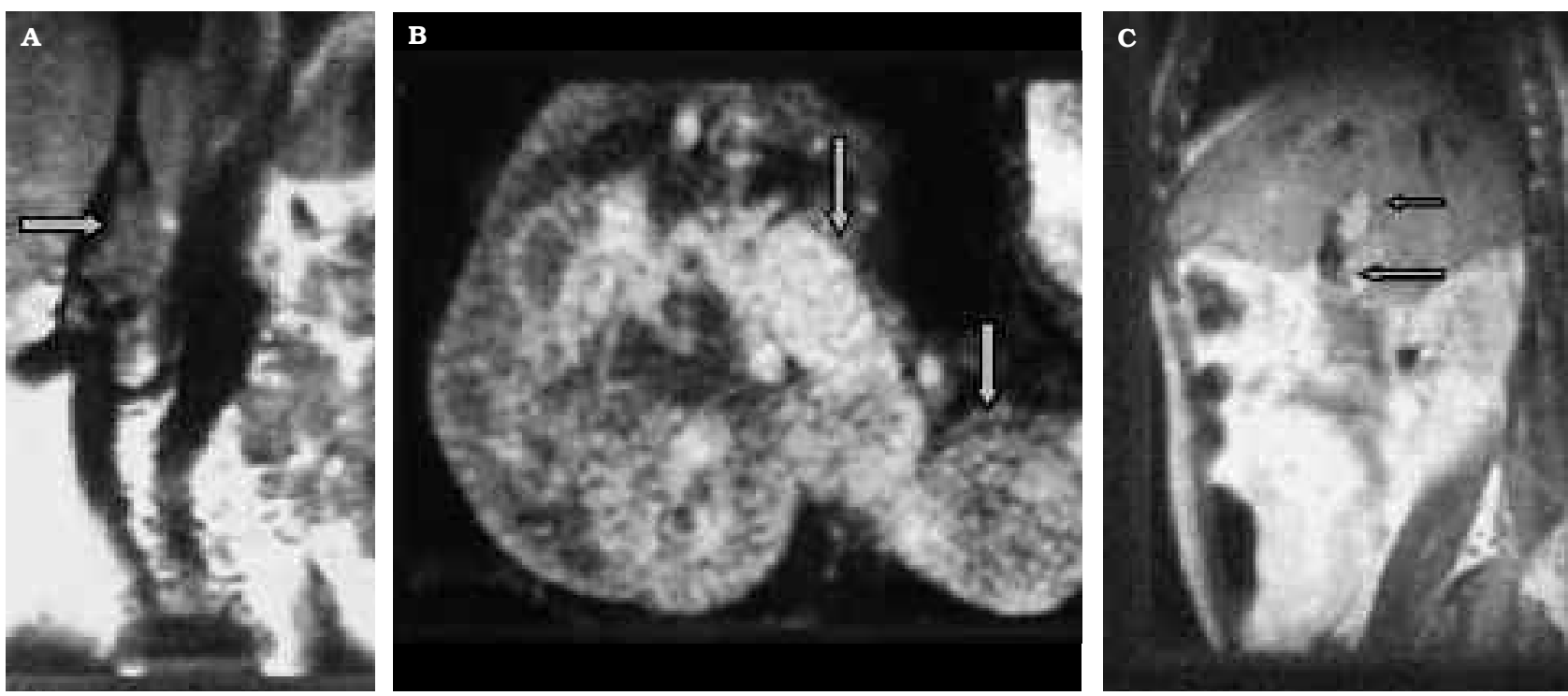

FIGURA 9. A) RMI coronal T1. Trombo tumoral VCI. 9) TC renal con medio de contraste yodado i.v. evidenciando trombo tumoral vascular en VRD y VCI. C) Imagen sagital RMI en T1 mostrando un trombo tumoral metastásico en vena porta y cambios de transformación varicosa de la red.

Linfomas no Hodgkin, es más frecuente. Puede ser causada por diseminación hematógena o por infiltración directa por contigüidad desde los ganglios linfáticos vecinos.

En TC, el linfoma renal se manifiesta en varias formas, con una afectación bilateral en el $75 \%$ de los casos. En imágenes sin medio de contraste, los riñones pueden aparecer normales o moderadamente incrementados de volumen. La infiltración de los tejidos perirrenales provocan un incremento de la densidad de la grasa. Pueden existir cambios multinodulares, a menudo con unos contornos renales lobulados. Este patrón es el más frecuente (45\%), en contraste con las lesiones renales circunscritas que se presentan en sólo el $15 \%$ de los pacientes o la infiltración difusa bilateral (10\%). La infiltración del riñón desde localizaciones retroperitoneales se pro-

duce en el 25\%. Las manifestaciones del linfoma extrarrenal implican al eje hepatoesplénico, nodos mesentéricos, para-aórticos, pélvicos y adrenales (Figs. 1la y b).

\section{TUMORES RENALES INFRECUENTES}

En este capítulo se agrupan el Fibroma, Hemangiopericitoma, el feocromocitoma renal, reninoma, leiomioma, hemangioma, linfangioma, sarcoma renal, carcinoide, histiocitoma fibroso benigno y los teratomas.

El sarcoma renal representa sólo un $1 \%$ de los tumores renales del adulto. Probablemente se origine de la cápsula renal. Habitualmente son tumores voluminosos y $1 / 3$ de ellos son palpables. Los sarcomas renales presentan una variable composición histológica, como el leiomiosarcoma (Figs. 12a, b, c y d), liposarcoma, rabdomiosar-
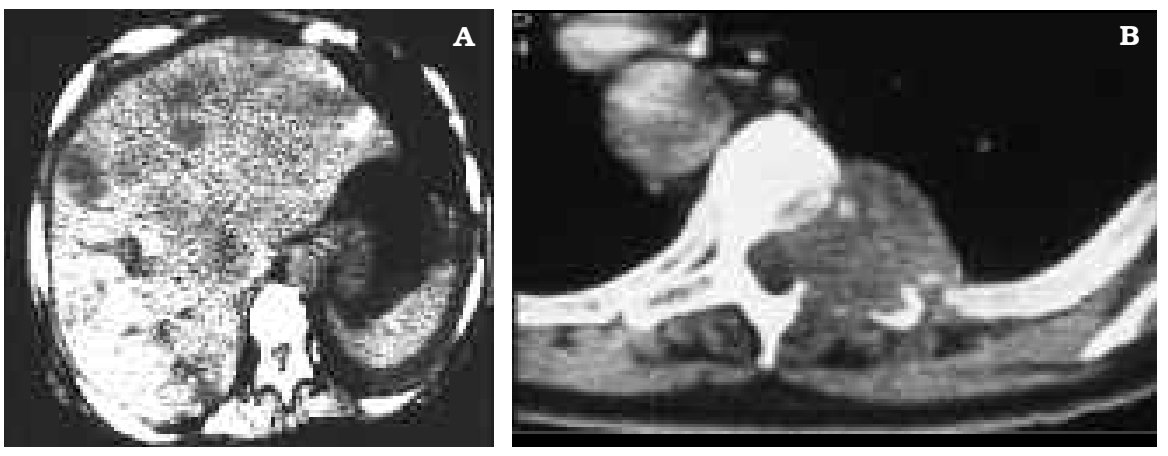

FIGURA 10. A y B) Imágenes TC en afectación metastásica del cancer renal. Múltiples lesiones ocupantes de espacio ( $\mathrm{LOE}$ 's ) en higado. Metástasis vertebral dorsal con afectación del canal medular y radicular. coma, histiocitoma fibroso maligno o fibroxantosarcoma y si presentan metástasis tempranas su pronóstico es muy desfavorable.

\section{RESUMEN Y CONCLUSIONES}

Ante cualquier efecto masa en el área renal, descubierto, bien mediante exploraciones de rutina ultrasonográficas o, a través de exploraciones TC no específi- 

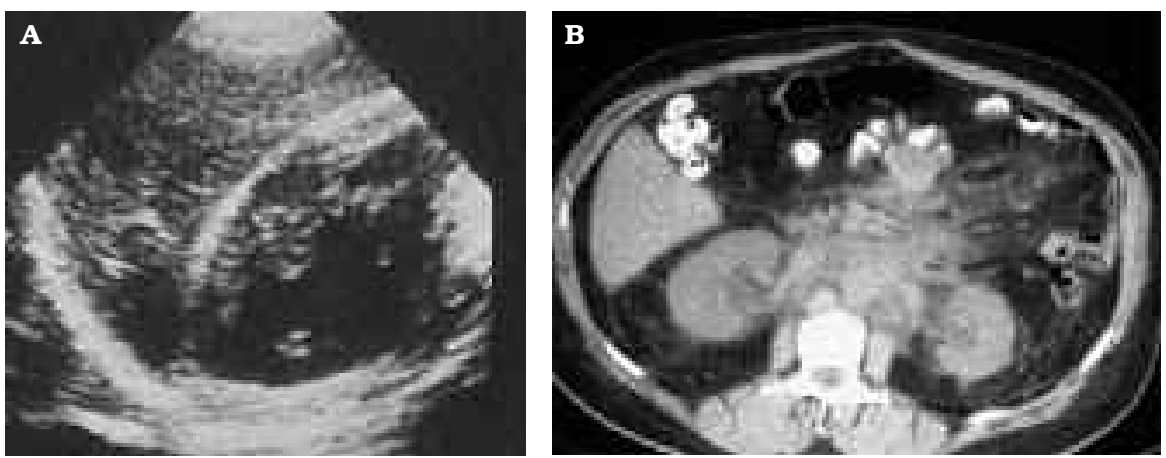

criterios de clasificación de la patología quística, no complicada y complicada, las características de enfermedades específicas como las hamartomatosis, la poliquistosis renal, patología inflamatoria no específica $\mathrm{y}$ específica, como la TB y PXG son fácilmente caracterizables mediante ultrasonografía. TC y FIGURA 11. A) Imagen ultrasonográfica renal derecha en un caso de Linfoma renal NoHodgkin primario del órgano. Desestructuración parenquimal . Patron infiltrativo difuso con ecoarquitectura dishomogenea. Preservacion de la grasa perinéfrica. B) Linfoma No-Hodgkin retroperitoneal con afectacion infiltrativa renal bilateral extranodal (Linfoma NH renal secundario).

RMI y aportan una semiología rica y determinada por la etiología y evolución de la enfermedad.

En las lesiones tumorales re-

cas o específicas de patología renal, se debe de protocolizar estrictamente al paciente para obtener una cadena de datos que nos permita efectuar una correlación anatomo-radiológica del proceso. Los
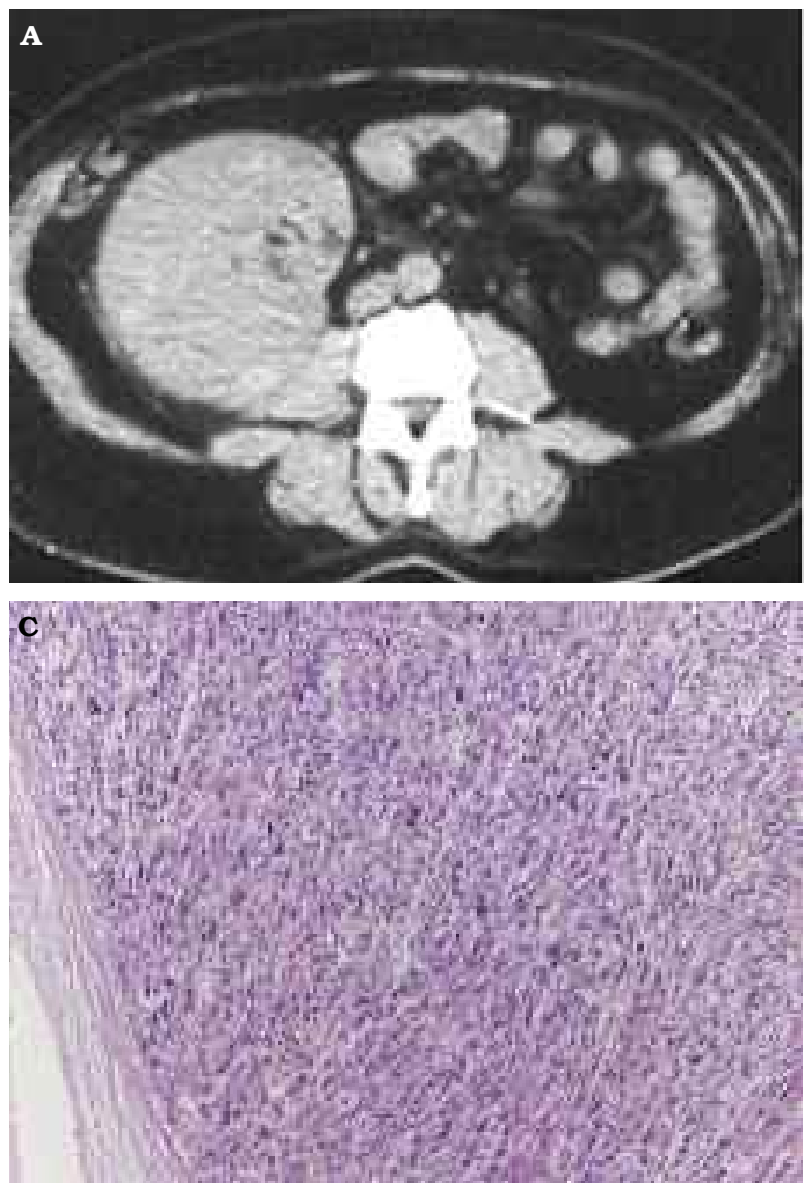
nales benignas y malignas es donde se encuentra la piedra angular de la caracterización. La diferenciación radiológica de adenoma-carcinoma en los estadios primarios, cuando la tumoración no
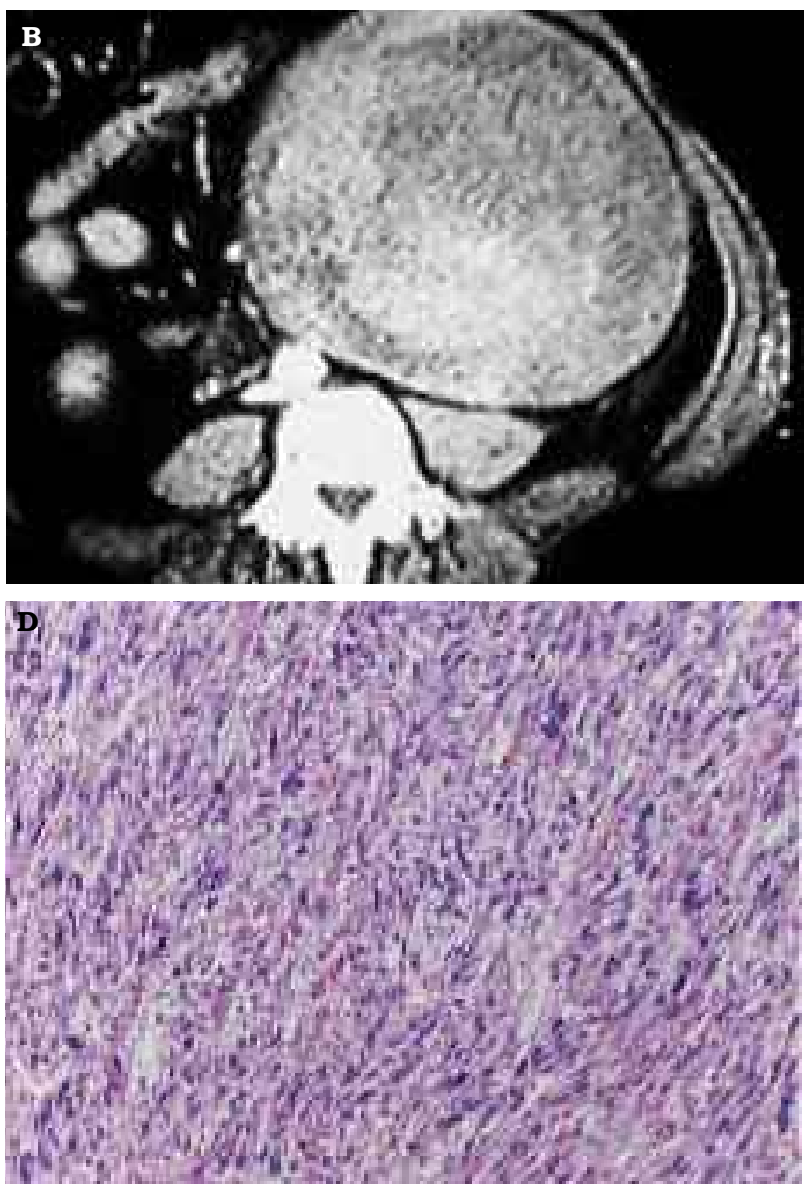

FIGURA 12. A) Leiomiosarcoma renal derecho en paciente monorreno. Tumor isodenso con músculo, homogeneo, bien circunscrito y definido, sin evidencia de necrosis. B) Leiomiosarcoma renal izquierdo. Realce dishomogeneo en el seno del tumor sin evidencia de áreas necróticas. Imágenes microscópicas de dos muestras de leiomiosarcoma. C) Apariencia de leiomioma. Se visualizan focos de hemorragia y necrosis. D) Evidencia de células de tipo fusiforme. Existe una variante mixoide. Contempla necrosis y pleomorfismo tisular con grado de mitosis variable. 
excede de los $20 \mathrm{~mm}$, es difícil. La profundización en las correlaciones radio-patológicas y el estudio de los modelos arquitecturales de los tumores y su visualización en las diferentes técnicas de diagnóstico por imagen nos permitan aportar más claves de especificidad de comportamiento biológicos y de su entidad histológica. Probablemente, las imágenes emergentes en técnicas celulares y moleculares basadas en técnicas de RM en imagen y espectroscópicas, en la utilización de medios de contraste específicos en ultrasonografía, en técnicas de SPECT o PET-TC-FDG podrán aportarnos muchos aspectos más sobre la biología tumoral.

Aspectos quirúrgicos relevantes como la extensión perirrenal y sus implicaciones en el tratamiento quirúrgico, de la extensión linfática o de la progresión tumoral venosa o metastásica pueden ser, relativamente eficientemente demostrados mediante técnicas de TC multidetector o RMI. Todo un reto: detección, localización, extensión, caracterización, planteamiento quirúrgico, pronóstico, toda una cadena de decisiones basadas en la relación de equipos multidisciplinares en donde urólogos, radiólogos, anatomo-patólogos, oncólogos, biólogos, fisiopatólogos y emergentes de las ciencias básicas y de la investigación tendrán que decidir los vectores de análisis y caracterización de las lesiones concernientes a la esfera renal.

\section{REFERENCIAS}

1. Bosniak MA. The current radiological approach to renal cysts. Radiology. 1986;158(1):1-10.

2. Israel GM, Bosniak,MA. How I do It: Evaluating renal masses. Radiology. 2005;236(2):441-450.

3. Balfe DM, McClennan BL, Stanley RJ, Weyman PJ, Sagel SS. Evaluation of renal masses considered indeterminate on computed tomography. Radiology. 1982;142(2):421-428.

4. Carlson DH, Carlson D, Evans DS. Benign multilocular cystic nephroma. Amr J Roentgenol. 1978;131(4):621-623.
5. Sussman S, Cochran ST, Pagani JJ, McArdle C, Wong W, Austin R, et al. Hyperdense renal masses: A CT manifestation of hemorrhagic renal cysts. Radiology. 1984;150(1):207-211.

6. Kier R, Taylor KJ, Feyock AL, Ramos IM. Renal masses: Characterization with Doppler US. Radiology. 1990;176(3):703707.

7. Birnbaum BA, Bosniak MA, Megibow AJ, Lubat E, Gordon RB. Observations on the gowth of renal neoplasm. Radiology. 1990;176(3):695-701.

8. Cohan RH, Sherman LS, Korobkin M, Bass JC, Francis IR. Renal masses: Assessment of corticomedullary- Phase and Nephrographic phase CT scans. Radiology. 1995;196(2):445451.

9. Bosniak MA. How does one deal with a renal cyst that appears to be Bosniak class II on a CT scan but that has sonographic features suggestive of malignancy (e.g., nodularity of wall or a nodular, irregular septum)?. AJR. 1994;163(1):216.

10. Bosniak MA. Problems in the radiologic diagnosis of renal parenchymal tumors. Urol Clin North Am. 1993;20(2):217-230.

11. Curry NS. Small renal masses (lesions samaller than $3 \mathrm{~cm}$ ) Imaging evaluation and management. AJR. 1995;164(2):355362.

12. Botella R, Herranz F. Adenocarcinoma renal: Hallazgos en Tomografía Computarizada y Resonancia Magnética. Urol Integr Invest. 2004;9(4):300-314.

13. Szolar DH, Kammerhuber F, Altziebler S, Tillich M, Breinl E, Fotter R et al. Multiphasic helical CT of the kidney: Increased conspicuity for detection and characterization of small $(<3 \mathrm{~cm})$ renal masses. Radiology. 1997;202(1):211-217.

14. Urban BA. The small renal mass: What is the role of multiphasic helical scanning?. Radiology. 1997;202(1):22-23.

15. Trinidad C, Maretinez C, Delgado C. Tumores Urológicos. En: Actualizaciones SERAM. Imagen en Oncologia. Ed. Panamericana.2009. pp.6789.

16. Jonisch AI, Rubinowitz AN, Mutalik PG, Israel GM. Can High attenuation renal cysts be differentiated from renal cell carcinoma an unenhanced CT?. Radiology. 2007;243:445-450.

17. Prasad SR, Humphrey PA, Catena JR, Narra VR, Srigley JR, Cortez $\mathrm{AD}$, et al. Common and uncommoen histologic subtypes of renal cell carcinoma: imaging spectrum with pathologic correlation. Radiograpghics. 2006;26(6):1795-1806.

Correspondencia autor: Dr. Javier Fernández Mena Departamento de Radiología y Medicina Física

Universidad de Granada

E-mail autor: jfm.rad@gmail.com

Información artículo: Original

Trabajo recibido: marzo

Trabajo aceptado: abril 